\title{
Strong Hearts, healthy communities: a rural community-based cardiovascular disease prevention program
}

\author{
Rebecca A. Seguin ${ }^{1 *}$, Galen Eldridge ${ }^{2}$, Meredith L. Graham ${ }^{3}$, Sara C. Folta ${ }^{4}$, Miriam E. Nelson ${ }^{4}$ and David Strogatz ${ }^{5}$
}

\begin{abstract}
Background: Cardiovascular disease is the leading cause of death in the United States and places substantial burden on the health care system. Rural populations, especially women, have considerably higher rates of cardiovascular disease, influenced by poverty, environmental factors, access to health care, and social and cultural attitudes and norms.
\end{abstract}

Methods/Design: This community-based study will be a two-arm randomized controlled efficacy trial comparing a multi-level, community program (Strong Hearts, Healthy Communities) with a minimal intervention control program (Strong Hearts, Healthy Women). Strong Hearts, Healthy Communities was developed by integrating content from three evidence-based programs and was informed by extensive formative research (e.g. community assessments, focus groups, and key informant interviews). Classes will meet twice weekly for one hour for 24 weeks and focus on individual-level skill building and behavior change; social and civic engagement are also core programmatic elements. Strong Hearts, Healthy Women will meet monthly for hour-long sessions over the 24 weeks covering similar content in a general, condensed format. Overweight, sedentary women 40 years of age and older from rural, medically underserved communities (12 in Montana and 4 in New York) will be recruited; sites, pair-matched based on rurality, will be randomized to full or minimal intervention. Data will be collected at baseline, midpoint, intervention completion, and six-month, one-year, and eighteen months post-intervention. The primary outcome is change in body weight; secondary outcomes include physiologic, anthropometric, behavioral, and psychosocial variables. In the full intervention, engagement of participants' friends and family members in partnered activities and community events is an intervention target, hypothesizing that there will be a reciprocal influence of physical activity and diet behavior between participants and their social network. Family members and/or friends will be invited to complete baseline and follow-up questionnaires about their health behaviors and environment, height and weight, and attitudes and beliefs.

Discussion: Strong Hearts, Healthy Communities aims to reduce cardiovascular disease morbidity and mortality, improve quality of life, and reduce cardiovascular disease-related health care burden in underserved rural communities. If successful, the long-term goal is for the program to be nationally disseminated, providing a feasible model to reduce cardiovascular disease in rural settings.

Trial registration: ClinicalTrials.gov Identifier: NCT02499731 Registered on July 1, 2015.

Keywords: Cardiovascular disease, Rural, Community, Nutrition, Diet, Exercise, Physical activity, Civic engagement, Health promotion, Evidence-based

\footnotetext{
* Correspondence: rs946@cornell.edu

'Division of Nutritional Sciences, Cornell University, Savage Hall, Room 412,

Ithaca, NY 14853, USA

Full list of author information is available at the end of the article
} 


\section{Background}

Despite declines in heart disease mortality in the United States since 2000, it remains the leading cause of mortality in both men and women-accounting for about one-third of all deaths in the U.S. Costs related to cardiovascular disease (CVD) place a substantial financial burden on the health care system, accounting for an estimated $\$ 320$ billion in 2011 [1, 2]. In addition, there is considerable disparity in CVD risk among individuals living in rural settings, particularly medically underserved rural areas and populations [3]. The combination of poverty, environmental factors (such as geographical distances and limited access to healthy foods and physical activity resources), as well as social and cultural attitudes and norms are important contributors to these rural health disparities and collectively compound the problem [4-8].

Another important consideration is gender disparity. Women living in rural areas tend to be uninsured, older, poorer, less educated, and have higher rates of chronic health conditions, and disabilities than their urban counterparts [9]. Rural midlife and older women are often isolated, without access to appropriate physical activity opportunities, affordable healthy food, and healthcare services [6-8, 10-26]. Importantly, women are also $20 \%$ more likely than men to die of heart disease; despite this, many women are unaware that they are at risk for CVD [27]. Fortunately, lifestyle modifications can reduce CVD risk among all age groups, including midlife and older women [28]. Women living in medically underserved areas are a critical target population for CVD prevention efforts. These women can act as powerful role models and agents of change for their families, friends, and communities [29, 30].

There is limited knowledge about how programs and services can move beyond commonly used individuallevel approaches, which have limitations in terms of cost, impact, reach, and sustainability, to effectively reduce rural CVD health disparities using an integrated, multilevel, community-engaged approach.

\section{Program background and development}

In 2002, the community-based StrongWomen Strength Training (SWST) program was developed, based upon two decades of clinical and community research that demonstrated the benefits of progressive strength training on midlife and older women's health-specifically muscular strength and mass, bone health, heart disease, diabetes, frailty, falls, arthritis, depression, and sleep $[31,32]$. A national dissemination initiative began in 2003 and there are now approximately 3,000 educators in 48 states trained to implement the SWST classes in their communities, with hundreds of classes operating throughout the U.S. and Canada [33]. In followup program evaluations, SWST participants demonstrated improvements in multiple domains of physical fitness (i.e. lower and upper body strength; lower and upper body flexibility; aerobic fitness; and agility) as well as body image and general physical activity behaviors [34, 35].

Ongoing feedback and collaboration with the educators leading those community-based classes catalyzed the development and testing of the StrongWomen Healthy Hearts (SWHH) physical activity and nutrition program. SWHH was tested in a randomized controlled efficacy trial with overweight and obese midlife and older women in Arkansas and Kansas. Results demonstrated significant reductions in body weight and improvements in diet and physical activity behaviors. The program has also been disseminated nationally [36-38].

The most recent addition to the StrongWomen programs is the StrongWomen Change Club (SWCC), which was developed, implemented, and evaluated in 2010-2011. The goal of this program was to promote community-level food and physical activity environment changes in non-urban communities through strategic civic engagement and capacity building activities [39]. One-year follow-up data with eight communities across the U.S. demonstrated the success of residents to identify an issue of concern in their community and work together in a step-wise process to gain broader community support and positively address the issue identified [39].

The Strong Hearts, Healthy Communities (SHHC) program, to be tested in this study, incorporates key elements from these three core StrongWomen curricula as the foundation of a new community-based program targeting CVD risk reduction for rural communities, specifically the strength training and aerobic exercise components from SWST and SWHH, respectively; nutrition education components and behavioral strategies from SWHH; and civic and social engagement strategies and activities from SWCC (also known as and referred to herein as the HEART Club, which is the name now used in this study and others).

Furthermore, to ensure a robust, appropriately tailored intervention, the development of the comprehensive SHHC approach incorporates partnerships with local health educators to conduct community assessments, focus groups, and key informant interviews with members of key groups to gather in-depth information about CVD awareness, economic, healthcare, and social/cultural issues, as well as barriers and facilitators to healthy eating, active living, smoking cessation, stress management, and other relevant topics. In addition, engagement of SHHC participants' friends and family members in partnered activities and community events is an intervention target, hypothesizing that there will be a reciprocal influence of physical activity and diet behavior between participants and their social network [29, 30]. 


\section{Methods/Design}

To best support sustainability, a CVD program for rural women living in medically underserved areas should be appropriately tailored and incorporate engagement and capacity building. Thus, the overall objectives of SHHC are to address the gap in knowledge and practice of approaches beyond individual-level change by testing a comprehensive program designed to: a) improve diet and physical activity behaviors, b) promote local built environment resources, and c) shift social norms about active living and healthy eating through civic engagement, capacity building, and community-based programming.

\section{Specific aims and related approaches}

\section{Aim 1: Facilitate broad community engagement, build}

\section{capacity, and conduct formative research; and}

\section{Aim 1.1: Develop and refine the SHHC curriculum}

Community assessments provide an in-depth look at area conditions, characteristics, features, and structures, such as housing, other buildings, schools, public spaces, parks, physical activity facilities, culture/entertainment, street use, commercial activity, signage, media, land use, public transportation, traffic, noise, faith services, health care facilities, community services/organizations, supermarkets, grocery stores, restaurants, and other food venues. The purpose of community assessments for this project is two-fold: 1) To provide community members and researchers with a "360 degree" perspective on the community strengths, resources, needs, and issues of concern; and 2) To develop a "Strong Hearts" resource guide for intervention communities. Information and experiences from the assessment are also important program sustainability tools, given that economic barriers often limit development of new community resources (e.g. parks), and seeing the community through a "new lens" helps identify existing resources that can be improved upon or "marketed." The overall goal of the assessment and resource guides is to address CVD risk factors (e.g. healthy eating, physical activity, preventive services, smoking cessation, stress management). The study team members, including the community health educators, will conduct walking and windshield tours of each community site. The windshield and walking tours are needed to provide detailed contextual information essential to development of the SHHC curriculum, and eventually to facilitate engagement and build capacity within the community.

Focus groups will occur in each of the study communities. We expect responses to key topic areas to vary substantially such that separate groups based on age and gender are justified. Groups will be stratified as such: age groups 40-64 and 65+; and male and female. Focus group participants (8-12 per group) will be recruited and screened by local health educators using a variety of community-based strategies, including press releases, flyers, and website posts. For focus group participants, there are three sources of data: 1) a screening form which will ask about age, BMI, sedentary lifestyle, employment status, and type of health insurance; 2) the focus group discussion, which covers awareness and knowledge about factors related to CVD risk; access to health care services and information; attitudes, perceptions, barriers, and facilitators to physical activity and eating heart-healthy diet; and understanding community in a rural environment; and 3) a short survey to be completed prior to the discussion designed to assess barriers related to attending intervention sessions, medical care seeking behaviors, meal patterns, smoking, and household size and income.

Key informant interviews will occur in study communities, with a total of 30 individuals. The goal is to confirm and extend findings from the community assessments and focus groups, and to provide in-depth perspectives from the communities. Topics will include perceptions of community risk and of environmental, policy, and community social/cultural factors that serve as barriers and facilitators to heart health behaviors. A purposive sample of approximately three key informants per town, representing health educators, practitioners, local leadership, or other stakeholders specific to a community as identified by extension educators will be selected for interviews.

The development of the SHHC and SHHW curricula will be informed by the community assessment, focus group, and key informant interview data and feedback from the local health educator partners along with a systematic content analysis and mapping to fully integrate the three foundational StrongWomen curricula. A national advisory board plus local health educator partners will also provide feedback and input during development of the curricula.

\section{Aim 2: Evaluate the efficacy of the SHHC intervention in a 24-week community-based randomized controlled trial; and Aim 2.1: Evaluate changes in behavior, attitudes, and knowledge among participants' social network}

We will evaluate the efficacy of the SHHC intervention on anthropometric, physiologic, behavioral, and psychosocial parameters among overweight and obese women aged 40 and older living in medically underserved rural communities. Sixteen communities, and approximately 12 women per community $(\mathrm{N}=192)$ will be randomized to either SHHC (8 communities) or the Strong Hearts, Healthy Women (SHHW; 8 communities), a minimal intervention control program (described below). There will be six intervention and six control communities in Montana and two intervention and two control communities in New York.

For Aim 2.1, study participants will be asked to identify $1-5$ of their closest family members and/or friends, 
who will then be invited to complete baseline and followup questionnaires. To evaluate changes among participants' social network members, we will collect pre- and post-intervention information about their health behaviors and environment, self-reported height and weight, attitudes and beliefs, and demographic variables.

\section{Participants}

\section{Towns/Communities}

To be eligible, communities must be classified as Ruralurban Commuting Area (RUCA) code 7 or higher and be designated as a medically underserved area (MUA) or population (MUP) by the Health Resources and Services Administration [40-42]. Within each state, communities are paired and geographically separate to reduce possible contamination effects. Additionally, the median household income of the selected communities must be at least $15 \%$ lower than for the corresponding state [43].

\section{Professionals delivering the intervention}

The local educators/coordinators who will lead implementation of the intervention, herein referred to as program leaders, will either be county extension educators/ agents (http://nifa.usda.gov/extension) or health educators affiliated with the local healthcare system. These program leaders will have extensive experience delivering similar programs to members of their communities. Program leaders and their coordinators will be trained in the study protocol and procedures; they will recruit and screen participants, as well as deliver the program to which they are randomized.

\section{Recruitment}

Program leaders and their coordinators will recruit women via flyers, community bulletin boards, social media, radio, direct mail postcards, and newspapers, as well as through churches, health care providers, human services, and "word of mouth." Recruitment of Aim 2.1 subjects will occur directly following the Aim 2 subjects' baseline assessment.

\section{Screening and eligibility}

Potential participants will be screened to ensure that they are in the target population using an Institutional Review Board (IRB)-approved screening form. All women who are eligible based upon initial screening will be required to obtain a signed healthcare authorization form from their healthcare provider indicating that exercise is safe and appropriate before they can begin. Once enrolled, subjects will discontinue the study if there are any changes in medical status that would make exercise unsafe.

\section{Inclusion criteria}

To qualify, participants must be female, 40 years old or older, have a BMI of 25 or greater, be currently sedentary, and English-speaking. They must also have their physician's approval and be willing to be randomized to either group. 'Currently sedentary' is defined as not meeting Physical Activity Guidelines for Americans or having an estimated total energy expenditure below $34 \mathrm{kcal} / \mathrm{kg}$ per day, per the 7-day Physical Activity Recall (PAR).

\section{Exclusion criteria}

Women will be ineligible to participate if they do not provide informed consent or permission from their healthcare provider, are hypertensive, have a heart rate less than 60 or greater than 100, have cognitive impairment, or are unwilling or unable to complete online questionnaires.

\section{Intervention curricula}

\section{Strong hearts, healthy communities}

The Strong Hearts, Healthy Communities (SHHC) intervention curriculum is the integration of three evidenceinformed community programs-two of which target primarily the individual level and a third that targets social and civic engagement. SHHC participants will meet twice per week for hourly sessions for 24 weeks (48 classes), as well as attend out-of-class monthly HEART club meetings (most of which are to be determined and designed by the group). The intervention programmatic components will focus on behavior change in the following areas: physical activity and fitness, weight loss, dietary improvement, and other CVD-related prevention skills and strategies such as stress management [34, 38, 44].

The diet component will include educational elements, aimed at changing dietary patterns informed by DASH (Dietary Approaches to Stop Hypertension) diet principles [45-48], the Dietary Guidelines for Americans [49], and the Mediterranean dietary pattern [50] focusing on practical, skill-building activities both in class (e.g. cooking skills, measuring true portion sizes, label reading) as well as field-based learning (e.g. grocery store audits and food environment assessments). The program's physical activities will be a combination of progressive aerobic exercise and strength training. There will also be out-of-class materials and assignments designed to involve friends and family members in program-related activities $[29,30]$.

The intervention's social and civic engagement components will include having SHHC groups work to identify a food or physical activity environment issue they believe is important and feasible to address in their community [39]. This could include adding crosswalks, signage, or bike lanes; it could include creating a healthy after-school or at-work food policy. To support their efforts, and to raise general awareness of local resources for healthy eating and active living, there will also be monthly meetings [39]. SHHC class members will help program leaders plan and implement these events. Example focus areas might 
include supporting local agriculture and farmers (e.g. healthy local food tasting expo at county fairs); recreation venues and assets for physical activity (e.g. town walkabout at a local park/trail); or health/wellness screening services (e.g. community cholesterol and blood pressure screening).

\section{Strong hearts, healthy women}

Participants in the minimal intervention program, called Strong Hearts, Healthy Women (SHHW), will meet six times-once per month for an hour for the six month time period. In this program, the nutrition and physical activity content and recommendations will be the same as the SHHC curriculum. The SHHW curriculum does not include a civic engagement component and the participants will not engage in in-class physical activity. It is expected that this minimal curriculum will provide the information to help improve knowledge, but will not provide the same level or amount of social support nor the stimulation for collective impact that SHHC provides.

\section{Staff training}

Program leaders will attend a $1 \frac{1 / 2}{2}$-day training workshop focused on the general research protocol and will attend a $1 / 2$ day follow-up intervention training for either SHHC or SHHW directly following randomization. Weekly implementation support calls will be held for all program leaders randomized to SHHC; monthly implementation support calls will be held for all SHHW program leaders.

\section{Data collection and outcomes}

Outcome assessment is planned across anthropometric, physiologic, behavioral, and psychosocial parameters. The study team at Cornell will oversee all online questionnairebased data collection, including dietary recalls and accelerometry data. An independent agency (Western Health Screening, described below) will travel to the Montana sites to collect the anthropometric and physiologic outcome data; in New York, this will be completed by locally trained staff affiliated with the healthcare system. The schedule for data collection, which occurs at baseline, midpoint (12 weeks), intervention completion (24 weeks) and six-month, one-year, and eighteen months postintervention, is shown in Table 1. Subjects in Aim 2.1 (family and/or close friends of Aim 2 subjects) will also complete items as indicated in Table 2 . All study activities are reviewed and approved by the Cornell IRB (file \# 1402004505) and Bassett Medical Center IRB (file \#2022).

\section{Measures}

Simple 7 and Framingham risk score Simple 7 is a cardiovascular health metric comprised of four health

Table 1 Data collection schedule: Aim 2 (SHHC and SHHW participants)

\begin{tabular}{|c|c|c|c|c|c|c|c|}
\hline Assessment & $\begin{array}{l}\text { Before } \\
\text { baseline } \\
\text { visit }\end{array}$ & $\begin{array}{l}\text { Baseline } \\
\text { visit }\end{array}$ & $\begin{array}{l}\text { Midpoint } \\
\text { assessment } \\
(12 \text { weeks) }\end{array}$ & $\begin{array}{l}\text { Final } \\
\text { assessment } \\
\text { (Post-intervention/ } \\
24 \text { weeks) }\end{array}$ & $\begin{array}{l}\text { Follow-up } \\
\text { assessment } 1 \\
\text { (6 months } \\
\text { post-intervention) }\end{array}$ & $\begin{array}{l}\text { Follow-up } \\
\text { assessment } 2 \\
\text { (12 months } \\
\text { post-intervention) }\end{array}$ & $\begin{array}{l}\text { Follow-up } \\
\text { assessment } 3 \\
\text { (18 months } \\
\text { post intervention) }\end{array}$ \\
\hline Informed consent form & $x$ & $x$ & & & & & \\
\hline Demographics & $x$ & & & & & & \\
\hline All questionnaires & $x$ & & & $x$ & & & $x$ \\
\hline HBEQ questionnaire only & & & $x$ & & $x$ & $x$ & \\
\hline Adverse event form & & & $x$ & $x$ & $x$ & $x$ & $x$ \\
\hline Midpoint satisfaction survey & & & $x$ & & & & \\
\hline Program satisfaction survey & & & & $x$ & & & \\
\hline 7-day Accelerometer & $x$ & & $x$ & $x$ & $x$ & & $x$ \\
\hline 7-day 24-hour Dietary recall & $x$ & & $x$ & $x$ & $x$ & & $x$ \\
\hline Blood draw & & $x$ & & $x$ & $x$ & & $x$ \\
\hline Skin scan & & $x$ & & $x$ & $x$ & & $x$ \\
\hline $\begin{array}{l}\text { All anthropometric measurements: } \\
\text { Waist and hip circumferences, } \\
\text { weight, height (baseline only), } \\
\text { body fat, bone density, body } \\
\text { composition, blood pressure, } \\
\text { and heart rate }\end{array}$ & & $x$ & & $x$ & $x$ & $x$ & $x$ \\
\hline $\begin{array}{l}\text { Selected anthropometric } \\
\text { measurements: Waist and hip } \\
\text { circumferences, weight }\end{array}$ & & & $x$ & & & & \\
\hline $\begin{array}{l}\text { Physical function tests } \\
\text { (arm curl, chair, two minute step) }\end{array}$ & & $x$ & $x$ & $x$ & $x$ & & $x$ \\
\hline
\end{tabular}


Table 2 Data collection schedule: Aim 2.1 (Social network members)

\begin{tabular}{|c|c|c|c|}
\hline Assessment & Baseline assessment & $\begin{array}{l}\text { Final assessment } \\
\text { (Post-intervention/24 weeks) }\end{array}$ & $\begin{array}{l}\text { Follow-up assessment } \\
\text { (6-months post-intervention) }\end{array}$ \\
\hline Informed consent form & $x$ & & \\
\hline Demographics & $x$ & & \\
\hline Self-reported height and weight (Height at baseline only) & $x$ & $x$ & $x$ \\
\hline Self-reported physical activity & $x$ & $x$ & $x$ \\
\hline Self-reported diet & $x$ & $\mathrm{x}$ & $x$ \\
\hline Attitudes and beliefs toward healthy eating and physical activity & $x$ & $x$ & $x$ \\
\hline
\end{tabular}

behaviors (i.e. smoking, body mass index, physical activity, healthy diet) and three health factors (i.e. total cholesterol, blood pressure, fasting glucose) $[51,52]$. They are characterized on a scale of poor, intermediate, or ideal health, which is correlated with prevalence of CVD events [53, 54]. We will use this approach to determine a Simple 7 cardiovascular health score at baseline and all post-intervention time points [54]. The Framingham Risk Score will also be calculated from questionnaire and physiologic data at baseline and post-intervention $[55,56]$. Age, smoking status, total cholesterol, HDL cholesterol, and systolic blood pressure are used to calculate the Framingham Risk Score.

Health behaviors environment, and quality of life This comprehensive questionnaire includes items related to nutrition and physical activity behaviors; environmental and social factors; other health behaviors (e.g. smoking); and limitations of activities due to health [4, 5, 57-65]. In addition, physical activity and sedentary behaviors will be measured using the 7-item International Physical Activity Questionnaire [66] and fruit and vegetable intake will be measured using the National Cancer Institute's Fruit and Vegetable Questionnaire [67].

Social support and self-efficacy Social support and self-efficacy for physical activity and diet will be measured using adapted versions of the Sallis tools [68-72].

Depression anxiety, stress, and resilience Depressive symptoms will be measured using the 8-item Patient Health Questionnaire (PHQ-8) [73]. The 7-item Generalized Anxiety Disorder scale (GAD-7) will be used to measure anxiety [74]. Stress will be measured using the 10-item Perceived Stress Scale (PSS) [75-77]. Resilience will be measured using the Brief Resilience Scale [78].

Eating behaviors The 21-item Three Factor Eating Questionnaire (TFEQ-R21) will be used to measure three eating behaviors: cognitive restraint, uncontrolled eating, and emotional eating [79-83].

Demographic variables (baseline only) Program leaders and all SHHC subjects will complete a questionnaire that includes basic demographic variables (e.g. age, race/ ethnicity, education, income, household size). Questions will be derived from national surveys (e.g. U.S. Census).

\section{Anthropometric and physiologic measures}

Anthropometric and physiologic data, including blood draws, will be collected by Western Health Screening (WHS) in Montana and by locally trained staff affiliated with the healthcare system in New York, with logistical support from program leaders and the study team. Blood will be drawn by trained, experienced phlebotomists. Anthropometric, physiologic, and dermal measures will all be taken at baseline and outcome assessments. For anthropometric and physiologic data, weight, hip circumference, and waist circumference measurements will be taken at the midpoint assessment (12 weeks).

Anthropometric measures These measures will include height, weight, BMI, body fat, bone density, hip circumference, waist circumference, and body composition. Freestanding height boards will be used for height measurements, and balanced scales will be used for weight calculations. The Omron HBF-306 will be used to measure body composition by electrical impendence. The Achilles Express and Insight will be used to measure bone density. A retractable Gulick tape measure will be used for hip and waist circumferences, rounded to the nearest 0.125 inch. Height, weight, and hip and waist circumferences will be measured in duplicate, unless specified criteria are not met for the two measurements. In that case, a third measurement will be taken. These anthropometric measurements are primary outcomes for the study.

Physiologic measures These measures will include blood pressure, resting heart rate, and fasting blood draws to assess 12-hour fasting glucose, hemoglobin $\mathrm{A} 1 \mathrm{C}, \mathrm{C}$-reactive protein, and lipid panel including direct LDL cholesterol, total cholesterol, HDL cholesterol, cholesterol/HDL ratio, and triglycerides [84].

Dermal measures As an objective measure of fruit and vegetable intake, study staff will use a Pharmanex 
BioPhotonic Scanner at baseline and outcome assessments, which non-invasively measures carotenoid levels in skin tissues using Raman Spectroscopy [85].

\section{Physical activity, diet, and functional fitness measures}

Measures of physical activity, diet, and functional fitness are secondary outcomes of the study.

Physical activity Objective measurement of physical activity will be obtained using the ActiGraph Model GT3XE accelerometers worn for seven days at baseline, midpoint (12 weeks), outcome (24 weeks), one year, and eighteen months.

Diet Dietary and supplement/vitamin intake will be collected and analyzed using seven automated selfadministered 24-hour dietary recalls (ASA-24) [86]. At least one weekend day recall will be collected and at least three weekday recalls will be collected at all study time points.

Functional fitness The chair test, bicep (arm curl) test, and 2-minute step test will follow the Senior Fitness Test protocol and be completed at baseline, 12-week, outcome (24 weeks), six months, and eighteen months [87]. The chair test and arm curl test consist of counting stands and arm curls completed in 30 seconds [87]. The 2-minute step test evaluates the number of times stepped in two minutes [87].

\section{Process evaluation}

Leader and participant-level process evaluation Leaders will complete questionnaires after each class session related to attendance, as well as program delivery and fidelity [88, 89], and for SHHC sites they will report on subjects' participation in HEART Club meetings and related activities. All SHHC participants will be provided with a Fitbit, a wireless activity tracker worn on the wrist, to enhance self-monitoring; they will be asked to share their Fitbit data with the study and that data along with the participant logs will provide on-going reported and objectively measured physical activity data. Participants will also be asked to complete a civic engagement questionnaire designed to assess awareness of local resources and civic engagement participation (past and current). Civic engagement attitudes and behaviors will be measured using the Civic Engagement Scale [90]. The questionnaire will be administered to all subjects at baseline and post-intervention.

Economic evaluation Standard economic evaluation methods will be used to compare the value of the resources used in the SHHC project to the health consequences. Information on salaries, wages and benefits; cost of facilities (office space and utilities); equipment, supplies, and travel; and staff training will be collected from program leaders. Information on time costs (participants' time at hourly wage rate), travel costs, and time spent exercising and planning/preparing meals will be collected from participants.

\section{Randomization}

The study statistician will determine randomization assignment based upon a matched RUCA and region classification such that, for paired towns, one will be randomized to SHHC and the other will be randomized to SHHW. Following baseline assessments, town randomization assignments will be revealed to program leaders and subjects.

\section{Data management and analytic plan}

Sample size calculations Based upon the most recent findings from the SWHH study [38], in which participants lost 2.1 kilograms $(\mathrm{SD}=2.6)$ over twelve weeks, it was determined that a sample size of 34 people per group will allow us to detect an effect size of 0.690 with a 2-sided test and a power of $80 \%$, conservatively allowing for a standard deviation of 3 . Given that the data are clustered within counties, we also assumed intra-class correlation of 0.025 (with clusters of 12 people) and $10 \%$ attrition [88], yielding a sample size requirement of 48 people per group (96 total) to obtain $80 \%$ power. This sample size will also allow us to have sufficient power to detect an effect size of 0.690 among secondary outcomes, such as blood pressure. For example, based on prior exercise intervention research with overweight and obese midlife and older women [91], an effect size of 0.690 would correspond to a $10 \%$ difference in systolic blood pressure with a standard deviation of approximately 24 .

Quantitative analysis Data will be collected online or double-entered into SPSS Data Builder by trained research personnel when needed. Univariate descriptive statistics for all variables will be examined. Problematic cases with outliers will be investigated and possibly rectified. Descriptive statistics by treatment groups will be compiled and tabulated. Comparison between conditions will be completed using chi-square test (binary and categorical variables), $t$-test (continuous variables), or non-parametric Wilcoxon Signed-rank test (continuous variables unsuitable for $t$-test). Since the observations are clustered within communities, we will use multilevel linear regression models to examine the unadjusted and adjusted effects of the intervention on the primary outcome (change in body weight) and secondary outcomes [physiologic (e.g. blood pressure, lipids, c-reactive protein, hemoglobin A1C); anthropometric (e.g. waist circumference); behavioral (e.g. 7-day accelerometry); and 
psychosocial (e.g. quality of life)] parameters using intentto-treat analysis. The community will be entered in the model as a random effect. Adjusted models will control for baseline values of the outcome, age, education level, marital status, smoking status, and other relevant covariates as fixed effects in addition to the treatment variable. Interactions between the treatment variable and other covariates will also be tested. Potential mediating effects of behavior, psychosocial, and community awareness/participation variables will be examined. In addition to the direct effect of the intervention on the primary outcome, the indirect effects of the intervention on anthropometric and physiologic outcomes through behavior, psychosocial, and community awareness/participation outcomes will be investigated. Multiple regression and/or structural equation modeling will be used to assess the contribution of various indirect and the direct effect of the intervention.

To address Aim 2, change variables for outcomes of interest (e.g. BMI) will be created by subtracting the measurement at 24 weeks from the corresponding baseline measure. A multilevel model will be used, as the observations are nested within communities. To account for the non-independence between observations from members of the same town, workplace, or household, a community and workplace/household ID will be entered in the model as a random effect. Intervention will be entered as a fixed independent variable. The model will control for baseline values of the outcome, age, education, marital status, smoking status, and other relevant covariates as fixed effects. Interaction terms will also be tested.

Economic analysis Standard economic evaluation methods will be used to compare the value of the resources used in the SHHC project to the health consequences. As a first step, a cost analysis to identify and measure the direct, tangible costs of the resources used in program administration and implementation will be conducted. Important cost categories are salaries, wages, and benefits; facilities (office space and utilities); equipment, supplies, travel, and staff training. The cost analysis will be conducted from the narrow program perspective and from the broad societal perspective. For the program perspective, the focus will be on costs directly incurred by the agencies that administer and implement the program. These costs will include both direct payments and the value of in-kind contributions, such as the value of contributed office space. The results of the program-perspective cost analysis will provide information to judge whether and where the SHHC can be disseminated. For this purpose, it will be important to distinguish the costs of different components of the SHHC, for example, the costs of SHHC program development as distinct from the costs of the SHHC intervention. The detailed results will allow groups considering dissemination to develop cost predictions tailored to their specific context.

A preliminary cost-effectiveness analysis (CEA) of the SHHC intervention will be conducted. The CEA will build on the cost analysis conducted from the broad societal perspective. From the societal perspective, costs include not only the costs included in the programperspective cost analysis, but also the opportunity cost of all resources used as a result of the intervention. Costs to participants are an important cost of the opportunity costs included from the societal perspective. Participants give up time that could have been used in other valued ways such as labor market work, household work, or leisure activities. Standard practice of measuring the value of participants' time based on the relevant wage rates will be followed. The incremental costs of the SHHC intervention will be compared to the incremental effectiveness estimated from the controlled trial. The incremental cost-effectiveness ratio (ICER) will be calculated by dividing the incremental costs of the intervention by the incremental effectiveness. The calculated ICER in terms of the primary outcome will provide an estimate of the costs per unit change in body weight. This ICER allows the direct comparison of the cost-effectiveness of the SHHC intervention to alternative approaches to reduce body weight. The ICER will also be calculated in terms of standardized health outcomes including life years and quality-adjusted life years (QALYs). Epidemiologic models will be used to map the effects measured in the controlled trial (body weight, physiologic measures) to predict impact on life years and QALYs. The calculated ICER in terms of QALYS will allow the cost-effectiveness of the SHHC to be compared to a wide range of other health interventions for which QALY-based CEAs have been performed. An important goal of the preliminary CEA is to demonstrate feasibility and identify important issues to be addressed in more complete economic analyses.

\section{Discussion}

There are notable disparities in risk for obesity, hypertension, diabetes, and CVD for people living in rural settings, particularly underserved rural areas. These disparities are driven by complex factors such as socioeconomic disadvantage, geographical distances/barriers, social and cultural issues, and limited access to healthcare, healthy foods, and/or physical activity opportunities due to environmental constraints, affordability, and availability. Moving beyond individual-level programs toward integrated, multi-level, community-engaged approaches may more effectively reduce rural CVD health disparities.

The novel integration of a multi-level, communityinformed program combined with civic engagement and capacity building focused on local resource awareness and enhancement has the potential to effect clinically 
meaningful improvements among participants, as well as their families, friends, and communities. This innovative approach will also help sustain positive changes by linking behavior, social support, and the community environment. If successful, SHHC could be nationally disseminated, providing a feasible model for underserved rural communities across the nation to improve health, well-being, and quality of life and reduce CVD and other chronic diseases.

\begin{abstract}
Abbreviations
ACSM: American College of Sports Medicine; ALB: Albumin; ALT: Alanine aminotransferase; AST: Aspartate aminotransferase; ASA-24: Automated Selfadministered 24-hour Recall; BMI: Body mass index; BUN: Blood urea nitrogen; CEA: Cost-effectiveness analysis; CVD: Cardiovascular disease; DASH: Dietary approaches to stop hypertension; EDTA: Ethylenediaminetetraacetic acid; GAD-7: Generalized anxiety disorder screener; GGT: Gamma-glutamyltransferase HBEQ: Health behavior and environment questionnaire; HDL: High-density lipoprotein; IBC: Iron binding capacity; ICER: Incremental cost-effectiveness ratio; IRB: Internal review board; LDH: Lactate dehydrogenase; LDL: Low-density lipoprotein; MUA: Medically underserved area; MUP: Medically underserved population; PAR: Physical activity recall; PHQ-8: Patient health questionnaire depression scale; QALY: Quality adjusted life years; RUCA: Rural urban continuum code; SHHC: Strong hearts, healthy communities;

SWCC: StrongWomen change club; SHHW: Strong hearts, healthy women; SWHH: StrongWomen healthy hearts; SPSS: Statistical package for the social sciences; SWST: StrongWomen strength training; TFEQ-R21: Three factor eating questionnaire; TSH: Thyroid stimulating hormone; WHS: Western health screening.
\end{abstract}

\section{Competing interests}

The authors declare that they have no financial or non-financial interests to declare.

\section{Authors' contributions}

RAS conceived of and is overseeing all aspects of the study and manuscript development. GE is participating in a variety of aspects of data collection and document editing and reviewed and approved the manuscript. MG is leading a variety of aspects of study implementation, data collection, and curriculum development; she also drafted and revised portions of the manuscript. SCF participated in study design and reviewed and approved the final manuscript. MEN participated in study design and reviewed and approved the final manuscript. DS participated in study design, is supporting study implementation, and has reviewed and approved the final manuscript. All authors read and approved the final manuscript.

\section{Acknowledgements}

We would like to acknowledge our funding from the National Heart, Lung and Blood Institute (R01 HL120702). We would also like to the contributions and efforts of our National Advisory Board members: KL Cason; MA Corbin; A Diffenderfer;

C Fogle; DS Kenkel; J May; D Nyquist; J Paddock; L Paul; JR Sharkey; L Tannehill; and N Wiker as well as the contributions and efforts of our program leaders and coordinators on the study: E Anderson; J Anderson; R Brown; A Burchak;

D Carey; L Davis; G Deuchler; L Eggen; L Fontaine; S Friedrich; A House; B Iverson; R LaFond; K Newland; L Olson; M Phillippi; K Pullybank; M Reed, J Riley, D Seilstad; K Seilstad; L Terry, J Turner; J Wolery; ; L Wyckoff; and $\mathrm{R}$ Younkin.

\section{Author details}

'Division of Nutritional Sciences, Cornell University, Savage Hall, Room 412, Ithaca, NY 14853, USA. ${ }^{2}$ Montana State University Extension, 235 Culbertson Hall, Bozeman, MT 59718, USA. ${ }^{3}$ Division of Nutritional Sciences, Cornell University, Savage Hall, Room 413, Ithaca, NY 14853, USA. ${ }^{4}$ Friedman School of Nutrition Science and Policy, Tufts University, 150 Harrison Avenue, Boston, MA 02111, USA. ${ }^{5}$ Center for Rural Community Health, Bassett Research Institute, One Atwell Road, Cooperstown, NY 13326, USA.
Received: 11 December 2015 Accepted: 19 January 2016

Published online: 28 January 2016

\section{References}

1. Roger V. Heart disease and stroke statistics-2012 update: a report rrom the American Heart Association. Circulation. 2012;125(22):E1002-2.

2. Mozaffarian D, Benjamin EJ, Go AS, Arnett DK, Blaha MJ, Cushman M, et al. Heart disease and stroke statistics-2015 update: a report from the American Heart Association. Circulation. 2015;131(4):e29-e322.

3. Cossman JS, James WL, Cosby AG, Cossman RE. Underlying causes of the emerging nonmetropolitan mortality penalty. Am J Public Health. 2010; 100(8):1417.

4. Boehmer TK, Lovegreen SL, Haire-Joshu D, Brownson RC. What constitutes an obesogenic environment in rural communities? Am J Health Promot. 2006:20(6):411-21.

5. Casey AA, Elliott M, Glanz K, Haire-Joshu D, Lovegreen SL, Saelens BE, et al. Impact of the food environment and physical activity environment on behaviors and weight status in rural US communities. Prev Med. 2008;47(6): $600-4$.

6. Sharkey JR. Measuring potential access to food stores and food-service places in rural areas in the US. Am J Prev Med. 2009;36(4):S151-5.

7. Krummel DA, Humphries D, Tessaro I. Focus groups on cardiovascular health in rural women: implications for practice. J Nutr Educ Behav. 2002; 34(1):38-46.

8. Perry CK, Rosenfeld AG, Bennett JA, Potempa K. Heart-to-Heart: promoting walking in rural women through motivational interviewing and group support. J Cardiovasc Nurs. 2007;22(4):304-12.

9. Winbush N, Crichlow R. Rural health care: a report from Montana and beyond. The Women's Health Activist. 2005;30:13-4.

10. Thornton L, Crawford D, Cleland V, Timperio A, Abbott G, Ball K. Do food and physical activity environments vary between disadvantaged urban and rural areas? Findings from the READI Study. Health Promot J Austr. 2012; 23(2):153-6.

11. Dean WR, Sharkey JR. Rural and urban differences in the associations between characteristics of the community food environment and fruit and vegetable intake. J Nutr Educ Behav. 2011;43(6):426-33.

12. Johnson CM, Sharkey JR, Dean WR. Eating behaviors and social capital are associated with fruit and vegetable intake among rural adults. Journal of Hunger and Environmental Nutrition. 2010;5(3):302-15.

13. Sharkey JR, Johnson CM, Dean WR. Food access and perceptions of the community and household food environment as correlates of fruit and vegetable intake among rural seniors. BMC Geriatr. 2010;10:32-2.

14. Rose D, Richards R. Food store access and household fruit and vegetable use among participants in the US Food Stamp Program. Public Health Nutr. 2004;7(8):1081-8.

15. Fisher BD, Strogatz DS. Community measures of low-fat milk consumption: comparing store shelves with households. Am J Public Health. 1999;89(2): 235-7.

16. Borra ST, Kelly L, Shirreffs MB, Neville K, Geiger CJ. Developing health messages: qualitative studies with children, parents, and teachers help identify communications opportunities for healthful lifestyles and the prevention of obesity. J Am Diet Assoc. 2003;103(6):721-8.

17. Montana Department of Public Health \& Human Services. Montana's Rural Health Plan. 2011.

18. Montana Department of Health \& Human Services. The burden of heart disease and stroke in the big sky state. 2007.

19. O'Connor A, Wellenius G. Rural-urban disparities in the prevalence of diabetes and coronary heart disease. Public Health. 2012;126(10):813-20.

20. Michimi A, Wimberly MC. Natural environments, obesity, and physical activity in nonmetropolitan areas of the United States. J Rural Health. 2012; 28(4):398-407.

21. Befort CA, Nazir N, Perri MG. Prevalence of obesity among adults from rural and urban areas of the United States: findings from NHANES (2005-2008). J Rural Health. 2012;392-7.

22. Sharkey JR, Johnson CM, Dean WR. Relationship of household food insecurity to health-related quality of life in a large sample of rural and urban women. Women Health. 2011;51(5):442-60.

23. Sharkey JR, Johnson CM, Dean WR. Less-healthy eating behaviors have a greater association with a high level of sugar-sweetened beverage consumption among rural adults than among urban adults. Food and Nutrition Research. 2011;55. 
24. McGuirt JT, Jilcott SB, Vu MB, Keyserling TC. Conducting community audits to evaluate community resources for healthful lifestyle behaviors: an illustration from rural eastern North Carolina. Prev Chronic Dis. 2011;8:6.

25. Hooker SP, Wilson DK, Griffin SF, Ainsworth BE. Perceptions of environmental supports for physical activity in African American and white adults in a rural county in South Carolina. Prev Chronic Dis. 2005;2:4.

26. Size T. Leadership development for rural health. N C Med J. 2006;67(1):71-6.

27. Agency for Healthcare Research and Quality. Cardiovascular disease and other chronic conditions in women: recent findings. Rockville, MD: Department of Health and Human Services; 2012.

28. Mozaffarian D, Fried LP, Burke GL, Fitzpatrick A, Siscovick DS. Lifestyles of older adults: can we influence cardiovascular risk in older adults? Am J Geriatr Cardiol. 2004;13(3):153-60.

29. Christakis NA, Fowler $\mathrm{JH}$. The spread of obesity in a large social network over 32 years. N Engl J Med. 2007:357(4):370-9.

30. Christakis NA, Fowler JH. Social contagion theory: examining dynamic social networks and human behavior. Stat Med. 2013;32(4):556-77.

31. Nelson M, Seguin R. Physical activity and older adults: impact on physical frailty and disability. In: Chodzko-Zajko WZW, editor. Measurement issues in aging and physical activity. Champaign, IL: Human Kinetics; 2006.

32. Seguin $R$, Nelson $M$. The benefits of strength training for older adults. Am J Prev Med. 2003;25(3):141-9.

33. Seguin RA, Economos CD, Hyatt R, Palombo R, Reed PNT, Nelson ME. Design and national dissemination of the StrongWomen Community Strength Training Program. Preventing Chronic Disease 2008;5(1).

34. Seguin R, Heidkamp-Young E, Kuder J, Nelson M. Improved physical fitness among older female participants in a nationally disseminated, communitybased exercise program. Health Educ Behav. 2012;39(2):183-90.

35. Seguin R, Eldridge G, Lynch W, Paul L. Strength training improves body image and physical activity behaviors among midlife and older women. Journal of Extension. 2013;51(4):4FEA2.

36. Folta SC, Lichtenstein AH, Seguin RA, Goldberg JP, Corbin MA, Wiker N, et al. The StrongWomen-Healthy Hearts program in Pennsylvania: RE-AIM analysis. Translational Behavioral Medicine. 2015;5(1):94-102

37. Folta SC, Seguin RA, Chui KK, Clark V, Corbin MA, Goldberg JP, et al. National dissemination of StrongWomen-Healthy Hearts: a communitybased program to reduce risk of cardiovascular disease among midlife and older women. Am J Public Health. 2015;105(12):2578-85.

38. Folta SC, Lichtenstein AH, Seguin RA, Goldberg JP, Kuder JF, Nelson ME. The StrongWomen-Healthy Hearts Program: reducing cardiovascular disease risk factors in rural sedentary, overweight, and obese midlife and older women. Am J Public Health. 2009:99(7):1271-7.

39. Seguin R, Heidkamp-Young E, Juno B, Knott A, Fenton M, Folta S et al. Community-based participatory research pilot initiative to catalyze positive change in local food and physical activity environments. International Journal of Behavioral Nutrition and Physical Activity 2012. Annual Meeting Oral Presentation.

40. Coburn A, Lundblad J, MacKinney A, McBride T, Mueller K. Designating health professional shortage areas and medically underserved populations/ medically underserved areas: a primer on basic issues to resolve. Columbia, MO: Rural Policy Research Institute, RUPRI Health Panel; 2010.

41. U.S. Department of Health and Human Services, Health Resources and Services Administration, National Center for Health Workforce Analysis: The U.S. health workforce-state profiles: Montana. Rockville, MD. 2014.

42. Find shortage areas: MUA/P by state and county [http://muafind.hrsa.gov/]

43. [https://www.census.gov/popest/data/]

44. Folta SC, Goldberg JP, Lichtenstein AH, Seguin R, Reed PN, Nelson ME: Factors related to cardiovascular disease risk reduction in midlife and older women: a qualitative study. Preventing Chronic Disease 2008, 5(1).

45. Appel LJ, Moore TJ, Obarzanek E, Vollmer WM, Svetkey LP, Sacks FM, et al. A clinical trial of the effects of dietary patterns on blood pressure. N Engl J Med. 1997;336(16):1117-24

46. Fung TT, Chiuve SE, McCullough ML, Rexrode KM, Logroscino G, Hu FB. Adherence to a DASH-style diet and risk of coronary heart disease and stroke in women. Arch Intern Med. 2008;168(7):713-20.

47. Obarzanek E, Sacks FM, Vollmer WM, Bray GA, Miller ER, Lin PH, et al. Effects on blood lipids of a blood pressure-lowering diet: the Dietary Approaches to Stop Hypertension (DASH) Trial. Am J Clin Nutr. 2001;74(1):80-9.

48. Sacks FM, Svetkey LP, Vollmer WM, Appel LJ, Bray GA, Harsha D, et al. Effects on blood pressure of reduced dietary sodium and the Dietary Approaches to Stop Hypertension (DASH) diet. N Engl J Med. 2001;344(1):3-10.
49. United States Department of Health and Human Services: Dietary Guidelines for Americans 2010. US Department of Agriculture, 7th edition Washington (DC): US Government Printing Office 2010.

50. Estruch R, Martínez-González MA, Corella D, Salas-Salvadó J, Ruiz-Gutiérrez V, Covas $\mathrm{Ml}$, et al. Effects of a Mediterranean-style diet on cardiovascular risk factors: a randomized trial. Ann Intern Med. 2006;145(1):1-11.

51. Tomaselli GF, Harty M-B, Horton K, Schoeberl M. The American Heart Association and the Million Hearts Initiative: a presidential advisory from the American Heart Association. Circulation. 2011;124(16):1795-9.

52. Million Hearts. Million Hearts Fact Sheet

53. Lloyd-Jones DM, Hong Y, Labarthe D, Mozaffarian D, Appel LJ, Van Horn L, et al. Defining and setting national goals for cardiovascular health promotion and disease reduction: the American Heart Association's Strategic Impact Goal through 2020 and beyond. Circulation. 2010;121(4): 586-613.

54. Folsom AR, Yatsuya H, Nettleton JA, Lutsey PL, Cushman M, Rosamond WD. Community prevalence of ideal cardiovascular health, by the American Heart Association definition, and relationship with cardiovascular disease incidence. J Am Coll Cardiol. 2011:57(16):1690-6.

55. Rodondi N, Locatelli I, Aujesky D, Butler J, Vittinghoff E, Simonsick E et al. Framingham risk score and alternatives for prediction of coronary heart disease in older adults. PLOS ONE. 2012;7(3).

56. Cleeman J, Grundy S, Becker D, Clark L. Expert panel on detection, evaluation and treatment of high blood cholesterol in adults. Executive summary of the third report of the National Cholesterol Education Program (NCEP) Adult Treatment Panel (ATP III). JAMA. 2001;285(19):2486-97.

57. Ware JE, Sherbourne CD. The MOS 36-item short-form health survey (SF-36). I. Conceptual framework and item selection. Med Care. 1992;30(6):473-83.

58. QualityMetric. SF-36v2 Health Survey. Lincoln, RI: QualityMetric Incorporated; 2012.

59. Epstein D. Network Spinal Analysis: a system of health care delivery within the subluxation-based chiropractic model. Journal of Vertebral Subluxation Research. 1996;1:51-9.

60. Jensen $G L$, Roy MA, Buchanan AE, Berg MB. Weight loss intervention for obese older women: improvements in performance and function. Obes Res. 2004:12(11):1814-20.

61. Gary R. Exercise self-efficacy in older women with diastolic heart failure: results of a walking program and education intervention. J Gerontol Nurs. 2006;32(7):31-9.

62. Cress ME, Buchner DM, Questad KA, Esselman PC, deLateur BJ, Schwartz RS. Exercise: effects on physical functional performance in independent older adults. J Gerontol A Biol Sci Med Sci. 1999;54(5):M242-8.

63. Li W-C, Chen Y-C, Yang R-S, Tsauo J-Y. Effects of exercise programmes on quality of life in osteoporotic and osteopenic postmenopausal women: a systematic review and meta-analysis. Clin Rehabil. 2009; 23(10):888-96.

64. Villaverde-Gutierrez C, Araujo E, Cruz F, Roa JM, Barbosa W, Ruiz-Villaverde G. Quality of life of rural menopausal women in response to a customized exercise programme. J Adv Nurs. 2006:54(1):11-9.

65. Vestergaard S, Kronborg C, Puggaard L. Home-based video exercise intervention for community-dwelling frail older women: a randomized controlled trial. Aging Clin Exp Res. 2008;20(5):479-86.

66. Craig C, Marshall A, Sjostrom M, Bauman A, Booth M, Ainsworth B, et al International physical activity questionnaire: 12-country reliability and validity. Med Sci Sports Exerc. 2003;35(8):1381-95.

67. Thompson F, Kipnis V, Subar A, Krebs-Smith S, Kahle L, Midthune D, et al. Evaluation of 2 brief instruments and a food-frequency questionnaire to estimate daily number of servings of fruit and vegetables. Am J Clin Nutr. 2000;71(6):1503-10.

68. Sallis JF, Pinski RB, Grossman RM, Patterson TL, Nader PR. The development of self-efficacy scales for health-related diet and exercise behaviors. Health Educ Res. 1988;3(3):283-92.

69. Sallis JF, Grossman RM, Pinski RB, Patterson TL, Nader PR. The development of scales to measure social support for diet and exercise behaviors. Prev Med. 1987;16(6):825-36.

70. Elfhag K, Rossner S. Who succeeds in maintaining weight loss? A conceptual review of factors associated with weight loss maintenance and weight regain. Obes Rev. 2005:6(1):67-85.

71. Eyler AA, Brownson RC, Donatelle RJ, King AC, Brown D, Sallis JF. Physical activity social support and middle- and older-aged minority women: results from a US survey. Soc Sci Med. 1999;49(6):781-9. 
72. Lawler SP, Winkler EAH, Goode AD, Fjeldsoe BS, Reeves MM, Eakin EG. Moderators of health behavior initiation and maintenance in a randomized telephone counseling trial. Prev Med. 2014;61:34-41.

73. Spitzer RL, Kroenke K, Williams JBW, Lowe B. A brief measure for assessing generalized anxiety disorder: the GAD-7. Arch Intern Med. 2006;166(10): 1092-7.

74. Kroenke K, Strine TW, Spitzer RL, Williams JBW, Berry JT, Mokdad AH. The PHQ-8 as a measure of current depression in the general population. J Affect Disord. 2009;114(1-3):163-73.

75. Cohen S, Williamson GM. Perceived stress in a probability sample of the United-States. In: Social Psychology of Health. Newbury Park, CA: Sage; 1988. p. 31-67.

76. Remor E. Psychometric properties of a European Spanish version of the Perceived Stress Scale (PSS). Span J Psychol. 2006;9(1):86-93.

77. Windle G, Hughes D, Linck P, Russell I, Woods B. Is exercise effective in promoting mental well-being in older age? A systematic review. Aging Ment Health. 2010;14(6):652-69.

78. Smith B, Dalen J, Wiggins K, Tooley E, Christopher P, Bernard J. The brief resilience scale: assessing the ability to bounce back. Int J Behav Med. 2008; 15(3):194-200.

79. Cappelleri JC, Bushmakin AG, Gerber RA, Leidy NK, Sexton CC, Lowe MR, et al. Psychometric analysis of the Three-Factor Eating Questionnaire-R21: results from a large diverse sample of obese and non-obese participants. Int J Obes (Lond). 2009;33(6):611-20.

80. French SA, Epstein LH, Jeffery RW, Blundell JE, Wardle J. Eating behavior dimensions. Associations with energy intake and body weight. A review. Appetite. 2012;59(2):541-9.

81. Bryant EJ, King NA, Blundell JE. Disinhibition: its effects on appetite and weight regulation. Obes Rev. 2008;9(5):409-19.

82. Teixeira PJ, Silva MN, Coutinho SR, Palmeira AL, Mata J, Vieira PN, et al. Mediators of weight loss and weight loss maintenance in middle-aged women. Obesity. 2010;18(4):725-35.

83. O'Reilly GA, Cook L, Spruijt-Metz D, Black DS. Mindfulness-based interventions for obesity-related eating behaviours: a literature review. Obes Rev. 2014;15(6):453-61.

84. Mora S, Rifai N, Buring JE, Ridker PM. Comparison of LDL cholesterol concentrations by Friedewald calculation and direct measurement in relation to cardiovascular events in 27,331 women. Clin Chem. 2009;55(5): 888-94

85. Dhurandhar N, Schoeller D, Brown A, Heymsfield S, Thomas D, Sørensen T, et al. Energy balance measurement: when something is not better than nothing. Int J Obes (Lond). 2014;39(7):1109-13.

86. National Cancer Institute. Automated Self-Administered 24-Hour Recall (ASA-24). Bethesda, MD; 2014

87. Rikli RE, Jones CJ. Senior Fitness Test Manual. Champaign, IL: Human Kinetics; 2012.

88. Folta S, Corbin M, Wiker N, Torock J, Lichtenstein A, Goldberg J et al. Dissemination of the StrongWomen - Healthy Hearts program in Pennsylvania: a study using the RE-AIM framework. International Journal of Behavioral Nutrition and Physical Activity 2012, Annual Meeting Oral Presentation.

89. Seguin RA, Palombo R, Economos CD, Hyatt R, Kuder J, Nelson ME. Factors related to leader implementation of a nationally disseminated community based exercise program: a cross-sectional study. International Journal of Behavioral Nutrition and Physical Activity. 2008;5.

90. Doolittle A, Faul AC. Civic Engagement Scale. SAGE Open. 2013;3(3):1-7.

91. Swift D, Earnest C, Katzmarzyk P, Rankinen T, Blair S, Church T. The Effect of Different Doses of Aerobic Exercise Training on Exercise Blood Pressure in Overweight and Obese Postmenopausal Women. Menopause. 2012;19(5): 503-9.

\section{Submit your next manuscript to BioMed Central and we will help you at every step:}

- We accept pre-submission inquiries

- Our selector tool helps you to find the most relevant journal

- We provide round the clock customer support

- Convenient online submission

- Thorough peer review

- Inclusion in PubMed and all major indexing services

- Maximum visibility for your research

Submit your manuscript at www.biomedcentral.com/submit

) Biomed Central 